\title{
ANALISIS SEMIOTIKA LOGO RESTAURAN SRIKANDI
}

\author{
Muhammad Sabri \\ Prodi Desain Komunikasi Visual \\ Fakultas Seni dan Desain Universitas Potensi Utama Medan \\ shabry92@gmail.com
}

\begin{abstract}
ABSTRAK
Srikandi merupakan sebuah nama tempat penjualan aneka makanan dan minuman dengan konsep lesehan keluarga dan penyajian masakannya yang di kemas seperti masakan desa yang mengutamakan kenyamanan dan kelezatan rasa dari masakan mereka. Penelitian logo restauran Srikandi ini mengunakan konsep semiotika Charles Sander Peirce dengan metode penelitian kualitatif. Logo Restauran Srikandi yang dibuat ini mencirikan identitas dari Restauran Srikandi itu sendiri, garis besar konsep yang di ambil dalam mendesain logo ini adalah lesehan keluarga, rotan, dan daun pisang. Warna yang dipakai pada logo tersebut memiliki tiga warna yaitu coklat, hijau dan putih, warna coklat untuk objek berbentuk sabit, warna hijau untuk hurufnya dan putih sebagai backgroundnya. Logo restauran Srikandi ini memiliki arti kenyamanan, kebersamaan, keluarga, romantis, suasana desa, alami, kebersihan.
\end{abstract}

Kata Kunci : Logo, Restauran, Semiotika dan Srikandi

\section{ABSTRACT}

Srikandi is the name of a place to sell various foods and drinks with the concept of family lesehan and the presentation of packaged dishes such as village cuisine which prioritizes the comfort and delicacy of their cuisine. The research of Srikandi restaurant logo uses Charles Sander Peirce's semiotic concept with qualitative research methods. The Logo Srikandi Restauran which was made characterizes the identity of the Srikandi Restaurant itself, an outline of the concept taken in designing this logo is family lesehan, rattan, and banana leaves. The colors used on the logo have three colors, namely brown, green and white, brown for crescent shaped objects, green for the letters and white as the background. The logo of the Srikandi restaurant means comfort, togetherness, family, romance, village atmosphere, nature and cleanliness.

Keywords : Logo, Restaurant, Semiotics and Srikandi,

\section{PENDAHULUAN}

Manusia merupakan makhluk hidup yang berkomunikasi menggunakan bahasa, oleh sebab itu manusia menggunakan bahasa sebagai media berkomunikasi dengan manusia 
lainnya. Verbal dan non-verbal adalah cara Manusia melakukan komunikasi. Komunikasi simbolis mengandalkan kesadaran mendalam dan karena itu menuntut penyertaan bahasa. bahasa simbolis menciptakan situasi yang simbolis juga. Yang makna, penuh dengan tanda tanya atau hal-hal yang mesti diungkapkan maksud dan makna yang terkandung didalamnya. Bahasa simbolis terdapat ditengah antara bahasa mistis dan alegoris seperti halnya pula berlaku dalam tindakan.

Komunikasi tidak hanya sebagai proses, tetapi juga komunikasi sebagai pembangun makna (the generation of meaning). Ketika kita berbicara terhadap orang lain, setidaknya orang tersebut mengerti arti dari pesan yang kita sampaikan, secara tepat. Agar komunikasi bisa tercapai, maka kita harus membuat pesan berbentuk tanda (bahasa, kata). Pesan-pesan yang kita buat, mendorong orang lain untuk membuat arti untuk dirinya sendiri yang terkait dalam beberapa hal dengan arti yang kita buat dalam pesan kita. Semakin sering kita berbagi kode yang sama, makin sering kita menggunakan sistem tanda yang sama, maka makin dekatlah "arti" kita dengan orang tersebut atas pesan yang datang pada masing-masing kita dengan orang lain tersebut.

Semiotika adalah ilmu yang mempelajari tentang tanda dan cara tanda-tanda itu bekerja (dikatakan juga semiologi). Dalam memahami studi tentang makna setidaknya terdapat tiga unsur utama yakni: (1) tanda, (2) acuan tanda, dan (3) pengguna tanda. Tanda adalah sesuatu yang bersifat fisik, bisa dipersepsi indra kita, tanda mengacu pada sesuatu di luar tanda itu sendiri, dan bergantung pada pengenalan oleh penggunanya sehingga disebut tanda.

Demikian juga logo, Logo adalah sebuah bentuk yang di sebut juga dengan sketsa gambar yang di visualisasi dari visi dan misi sebuah perusahaan atau organisasi maupun jenis produk. Sebuah logo perusahaan atau organisasi akan di katakan sukses apa bila perusahaan tersebut mempunyai ciri khas brand tersendiri yang mudah diterima oleh ingatan masyarakat sebagi pengganti nama perusahaan atau organisasi tersebut. Saat ini, logo semakin dibutuhkan orang, bukan hanya pada setiap perusahaan maupun produk, tetapi dalam setiap karakter dibutuhkan logo agar supaya merefleksikan ciri khas dari pengguna logo tersebut.

Restauran Srikandi merupakan sebuah nama tempat penjualan aneka makanan dan minuman yang berupa lesehan keluarga yang berlokasi di daerah jalan Tanah Enam Ratus Medan dengan ciri khasnya yaitu penyajian masakannya yang di kemas seperti masakan 
kampung menggunakan piring yang terbuat dari bahan rotan yang di lapisi dengan daun pisang dan wadah nasi yang terbuat dari anyaman bambu namun dalam hal ini Srikandi tetap menjaga dan mengutamakan kenyamanan dan kelezatan rasa dari masakan mereka.

Elemen-elemen yang ada dalam sebuah logo dirasa mempunyai pesan yang sama dengan visi, misi, jiwa dan kepribadian perusahaan tersebut. Ilmu tentang tanda dan segala yang berkaitan dengannya adalah ilmu semiotik. Pada semiotik semua yang dilihat atau dibuat dapat didefinisikan, mengacu pada hal yang merujuknya, dan bisa diinterpretasikan, adalah tanda. Dengan menggunakan akal sehatnya, seseorang biasanya mengkaitkan sebuah tanda pada rujukan (reference) agar memahami arti tersebut. Berdasarkan latar belakang itu, penulis membuat penelitian yang berjudul "Analisis Semiotika Logo Srikandi”

\section{STUDI LITERATUR}

Logo adalah sebuah bentuk yang di sebut juga dengan sketsa gambar yang di visualisasi dari visi dan misi sebuah perusahaan atau organisasi maupun jenis produk. Sebuah logo perusahaan atau organisasi akan di katakan sukses apa bila perusahaan tersebut mempunyai ciri khas brand tersendiri yang mudah diterima oleh ingatan masyarakat sebagi pengganti nama perusahaan atau organisasi tersebut. Kusrianto, Adi. (2009 : 2).

Secara etimologi yang mempelajari asal usul dari suatu kata, kata semiotik bermula dari istilah Yunani yaitu semeion yang memiliki arti tanda. Tanda tersebut merupakan sesuatu hal yang terdapat pada masyarakat yang sudah terjadi sebelumnya, kemudian menjadi kebiasaan dan memiliki makna yang sama dengan sesuatu yang berbeda (Eco, 1979:16).

Penyebutan semeion tampaknya diturunkan dari kedokteran hipokratik atau asklepiadik dengan perhatiannya pada simtomatologi dan diagnostik inferensial (Sinha, dalam Kurniawan, 2001:49). Tanda pada saat tersebut masih berarti sesuatu hal yang merunjuk pada sesuatu hal lain. Misalnya seperti, asap menandai adanya api. Secara terminologis, semiotik dapat di artikan sebagai ilmu yang mempelajari beberapa luas objek dan kejadian, serta semua kebudayaan sebagai tanda (Eco, 1979:6).

Van Zoest (1996:5) mendefinisikan semiotika sebagai "ilmu tanda (sign) dan segala yang berhubungan dengannya: cara berfungsinya, hubungannya dengan kata lain, pengirimannya, dan penerimaannya oleh mereka yang mempergunakannya”. 
Sobur, Alex. (2009:95-96) telah mengutip statement yang Dikatakan oleh Preminger (2001:89) bahwa "semiotik adalah ilmu tentang tanda-tanda. Ilmu ini menganggap bahwa fenomena sosial atau masyarakat dan kebudayaan itu merupakan tanda-tanda. Semiotik itu mempelajari sistem, aturan-aturan, konvensi-konvensi yang memungkinkan tanda-tanda tersebut mempunyai arti”. Semiotik merupakan sebuah cara atau ilmu yang mempelajari tentang menganalisis untuk mengkaji tanda. Tanda-tanda adalah perangkat yang kita pakai dalam upaya berusaha mencari jalan di dunia ini, ditengah-tengah manusia dan bersamasama manusia.

Semiotika komunikasi visual merupakan suatu keilmuan yang memberikan suatu interpretasi kepada keilmuan semiotik tersendiri, yaitu semiotika suatu cara atau alat melihat dan mendefinisikan karya komunikasi visual. Semiotika merupakan ilmu yang membahas tentang tanda (sign), berfungsinya tanda, dan produksi makna. Tanda adalah sesuatu yang bagi seseorang berarti sesuatu yang lain Tinarbuko, Sumbo. (2009 :17).

\section{PEMBAHASAN}

\section{A. Penjelasan}

Pada penelitian logo Restauran Srikandi ini peneliti menggunakan metode kualitatif. Penelitian kualitatif merupakan penelitian yang lebih cenderung secara perspektif subjek. Pada penelitian ini Peneliti akan mendeskripsikan suatu objek logo dengan cara menganalisa objek logo tersebut, kemudian melakukan riset lapangan dengan cara terjun langsung ke Restauran Srikandi untuk mendapat gambaran seperti apa keadaan yang sebenarnya pada tempat tersebut dan peneliti juga melakukan wawancara terhadap pemilik restauran Srikandi dan beberapa karyawan yang ada di tempat tersebut. Setelah dilakukan observasi dan wawancara yang di lakukan pada restauran Srikandi maka di peroleh data data yang relevan. Kemudia data-data tersebut di kaitkan dengan konsep semiotika Charles Sander Peirce. 


\section{B. Visualisasi Logo Restauran Srikandi}

Adapun desain logo restauran srikandi tersebut adalah sebagai berikut:

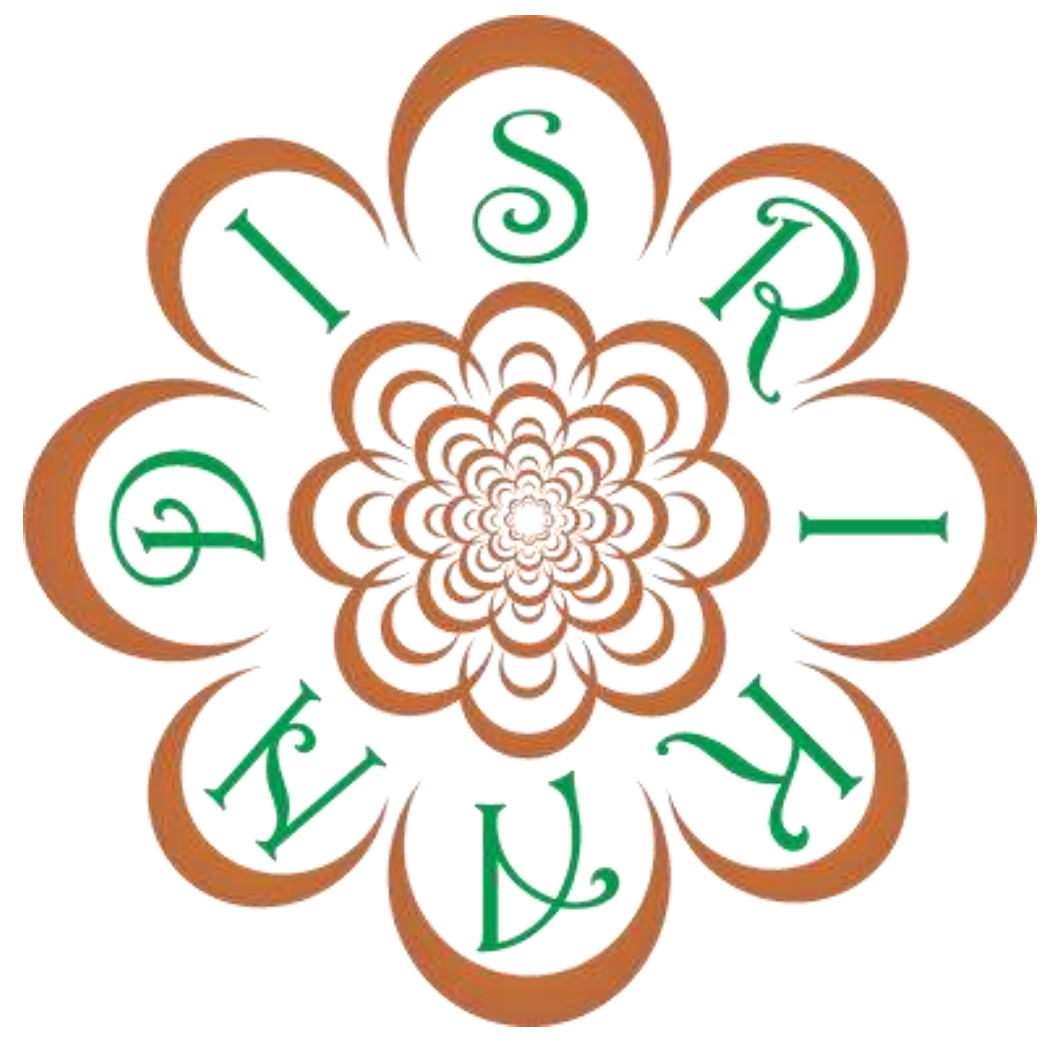

Gambar 1. Logo Restauran Skrikandi

Logo Restauran Srikandi ini memiliki bentuk dasar geometris bulat dengan visualnya berbentuk sabit-sabit yang disusun sedemikian rupa sehingga menjadi sebuah lingkaran dan di dalam masing-masing sabit tersebut terdapat huruf ejaan dari nama restauran tersebut yaitu huruf S. R. I. K. A. N. D. I. Kemudian pada bagian tengah terdapat beberapa sabit ada yang besar dan kecil yang disusun sedemikian rupa sehingga berbentuk seperti bunga. Warna yang dipakai pada logo tersebut memiliki tiga warna yaitu coklat, hijau dan putih, warna coklat untuk objek berbentuk sabit, warna hijau untuk hurufnya dan putih sebagai backgroundnya.

\section{Hasil Analisis}

Hasil dari Analisis yang telah di lakukan terhadap logo Restauran Srikandi ini adalah sebagai berikut : 
Srikandi merupakan sebuah nama tempat penjualan aneka makanan dan minuman dengan konsep lesehan keluarga dan penyajian masakannya yang di kemas seperti masakan desa yang mengutamakan kenyamanan dan kelezatan rasa dari masakan mereka. Logo Restauran Srikandi yang dibuat ini mencirikan identitas dari Restauran Srikandi itu sendiri, garis besar konsep yang di ambil dalam mendesain logo ini adalah lesehan keluarga, rotan, dan daun pisang. Warna yang dipakai pada logo tersebut memiliki tiga warna yaitu coklat, hijau dan putih, warna coklat untuk objek berbentuk sabit, warna hijau untuk hurufnya dan putih sebagai backgroundnya

1. Analisa logo restauran Srikandi dilihat dari tanda yaitu ikon, indeks dan symbol sebagai berikut.

a. logo restauran Srikandi terdapat tanda ikon antara lain sabit dan bunga

b. logo restauran Srikandi terdapat tanda indeks antara lain sabit, lingkaran, bunga, kursi, pelanggan, meja dan piring rotan.

c. logo restauran Srikandi terdapat tanda simbol antara lain warna coklat, hijau, putih, bunga, lingkaran dan Huruf .

2. Arti dari logo restauran Srikandi

Analisa logo restauran Srikandi menggunakan konsep semiotika Charles Sander Peirce adalah sebagai berikut :

a. Linkaran : memiliki arti kebersamaan, keakraban, keluarga, ramah dan kenyaman

b. Sabit : memiliki arti lesehan, kursi duduk

c. Huruf : mewakili pengunjung atau pelanggan yang sedang duduk melingkar, dan Nama dari Restauran itu sendiri.

d. Bunga : diambil dari bentuk piring rotan, mewakili bentuk meja bundar, yang memiliki arti romantis, sosialisasi, dan hubungan

e. Sabit-sabit kecil tidak beraturan : mewakili hidangan makanan dan memiliki arti perusahaan yang berjalan dinamis.

i. Warna coklat : diambil dari warna piring rotan, bambu kering, kayu, yang memiliki arti suasana desa, alam, kekeluargaan

j. Warna hijau : diambil dari warna daun pisang, yang memiliki arti alami, natural, tumbuh dan selalu diperbarui.

k. Warna putih : usaha yang peduli akan kebersihan.. 


\section{KESIMPULAN}

Penelitian logo restauran Srikandi ini mengunakan konsep semiotika Charles Sander Peirce dengan metode penelitian kualitatif. Logo Restauran Srikandi yang dibuat ini mencirikan identitas dari Restauran Srikandi itu sendiri, garis besar konsep yang di ambil dalam mendesain logo ini adalah lesehan keluarga, rotan, dan daun pisang. Warna yang dipakai pada logo tersebut memiliki tiga warna yaitu coklat, hijau dan putih, warna coklat untuk objek berbentuk sabit, warna hijau untuk hurufnya dan putih sebagai backgroundnya. Logo restauran Srikandi ini memiliki arti kenyamanan, kebersamaan, keluarga, romantis, suasana desa, alami, kebersihan.

\section{DAFTAR PUSTAKA}

[1] Adi, Kusrianto. 2007. Pengantar Desain Komunikasi Visual. Yogyakarta: Andi Offset

[2] Barthes, Roland. 1988. The Semiotics Challenge. New York: Hill and Wang

[3] Cobley, Paul \& Litza Jansz. 2002. Mengenal Semiotika for Beginners. Bandung: Mizan Media Utama (MMU)

[4] Danesi, Marcel. 2010. Pesan, Tanda, dan Makna: Buku Teks Dasar Mengenai Semiotika dan Teori Komunikasi. Yogyakarta : Jalasutra

[5] Eco, Umberto. 1979. Theory of Semiotics. Bloomington: Indiana University press.

[6] Hoed, B.H. 2008. Semiotik dan Dinamika Sosial Budaya. Depok: Fakultas Ilmu Pengetahuan Budaya. Universitas Indonesia.

[7] Martinet, Jeanne. 2010. Semiologi, Kajian Teori tanda Saussuran. Yogyakarta : Jalasutra.

[8] Mulyana, Deddy. 2005. IlmuKomunikasi: Suatu Pengantar. Bandung: Remaja Rosdakarya.

[9] Sobur, Alex. 2006. Semiotika Komunikasi. Bandung: PT Remaja Rosdakarya.

[10] Sobur, Alex. 2006. Semiotika Komunikasi. Bandung: PT Remaja Rosdakarya.

[11] Sugiyono.2011. Metode Penelitian Kuantitatif dan Kualitatif dan R\&D. Bandung : Alfabeta.

[12] Wibowo, Indiawan Seto Wahyu. 2011. Semiotika Komunikasi.Jakarta. 